\title{
Exploring the Concept of Acronyms form a Morphological Viewpoint
}

\author{
Mohamed Said Ahmed Alawad* \\ Sudan University of Science and Technology, Graduate College \\ *Corresponding Author: Mohamed Said Ahmed Alawad, Sudan University of Science and Technology, \\ Graduate College, Sudan
}

\begin{abstract}
We live in a tremendously rapid world with ever accelerating quick tempo which necessitates rapidity in all walks of life. So, Life is moving with surprising swiftness or amazing quick tempo, everything is done quickly. There in no time is an expression heard quite often everywhere, people even always want to have things without delay that happened in different forms of life and generated new expression began to be used as normal words. Even at international telecommunication (IT). Also at industries, medication, military, education, sciences, politician, society legal treatments, sports, economic as a whole, every aspects of life you are going to face with huge number of acronyms or abbreviation or short out words.
\end{abstract}

Keywords: Tremendous, Quick Tempo, Acronym, Telecommunication, Aspects of Life

\section{INTRODUCTION}

Swiftness is the salient characteristics of our modern time. The intention of this behavior is to respond to modern life needs. Folk are in a hurry, everything is done quickly, people have realized the importance of time, and the value of minutes or seconds. When you stand at take away food, you find no much seats are available why because he buyers are in a hurry, they want fast food. Staying at home, asking for your personal needs through internet, they are going to bring your things in no time. So clothes, shoes, books, doctors , maintenance ...etc. that sort of life has become the model of today life modernization has no patience for waiting just keep moving, even you notice this at literature books, shortcuts are much and acronyms are many !! Why for, they say modernization. Economic, it's a new style of life, others say, no it is old began since at the Greek area, the purpose of it to give a brief about adjectives or qualifications. Now we have followed the suit, but in other words, the frame is one but the output is different. That, what we are going to discover later on. Today's life in treatments specially merchant's has become easier specifically at airports, commercial places, medicine industries that was really seen and tangible at civilized people in Europe where people are used to such way of life openly, other continent are creeping to copy the best. So this research is an attempt to know more about this modern science and to shed light on it, to know how it began, and where and how can we get it, the better use of it as a new jargon entered our modern life smoothly but positively. The way of understanding this science is not difficult, because it based on the vocabulary you have and to harness it for your benefit. So as to ease life dealing and handling, that is the main objective of acronyms.

Recently needs: for quick work is clearly seen at different places like airports, where directions are all written in initials letters ...newspapers show acronyms stand for posts, ministries, also at pharmacies where medicines are sold likewise at literature books, where names, places, roads or even general places are written in abbreviation. That and this are the life stereotype, where people are forced to do things in seconds, so as to gain time, and this the main objective of acronyms.

Although the word acronym is often used to refer to any abbreviation formed from initial letters some dictionaries and usage commentators define acronym to mean an abbreviation that is pronounced as a word in contrast to an initialism (or alphabetism) - an abbreviation formed from a string of initials (and possibly pronounced as individual letters). Some dictionaries include additional senses. 


\section{ENGLISH MORPHOLOGY}

This is an important area of English Language. Morphology is the study of word structure and word formation. A morpheme is the smallest grammatical unit in a language that carries meaning. Morphology is important for English Language Learners because it breaks down language and creates patterns of meaning for speakers. Learning English isn't simply about reading sentences and words, rather to truly know English the speaker must be able to make meaning of the sounds within words. For example, once a speaker understands the morpheme of [s] or [ing], they will be able to apply and comprehend that construct of language with many different words.

As human beings, we have been endowed with such huge brains that are capable of storing great numbers of words. James (2007:67) states that "language creates unreal worlds and allows us to talk about non-existing things" Even a child might utter a sentence that has never said before. Nevertheless, it is seems impossible for a person to understand, generate, and use the function of each word because, apart from the words that a person knows and are stored in his/her mental lexicon, there might be words that have never been heard before by the same person. Language is a subject and is on a process of continuous change.

The existence of words is usually taken for granted by the speakers of a language. To speak and understand a language means - among many other things - knowing the words of that language. The average speaker knows thousands of words, and new words enter our minds and our language on a daily basis. This book is about words.

More specifically, it deals with the internal structure of complex words, i.e. words that are composed of more than one meaningful element. Take, for example, the very word meaningful, which could be argued to consist of two elements, meaning and -ful, or even three, mean, -ing, and -ful. We will address the question of how such words are related to other words and how the language allows speakers to create new words. For example, meaningful seems to be clearly related to colorful, but perhaps less so to awful or plentiful. And, given that meaningful may be paraphrased as 'having (a definite) meaning', and colorful as 'having (bright or many different) colors', we could ask whether it is also possible to create the word coffeeful, meaning 'having coffee'. Under the assumption that language is a rule-governed system, it should be possible to find meaningful answers to such questions.

\section{WHAT IS A WORD}

It has been estimated that average speakers of a language know from 45,000 to 60,000 words. This means that we as speakers must have stored these words somewhere in our heads, our so-called mental lexicon. But what exactly is it that we have stored? What do we mean when we speak of 'words'?

In non-technical every-day talk, we speak about 'words' without ever thinking that this could be a problematic notion. In this section we will see that, perhaps contra our first intuitive feeling, the 'word' as a linguistic unit deserves some attention, because it is not as straightforward as one might expect.

If you had to define what a word is, you might first think of the word as a unit in the writing system, the so-called orthographic word. You could say, for example, that a word is an uninterrupted string of letters which is preceded by a blank space and followed either by a blank space or a punctuation mark. At first sight, this looks like a good definition that can be easily applied, as we can see in the sentence in example (1):

\section{(1) Linguistics is a fascinating subject}

We count 5 orthographic words: there are five uninterrupted strings of letters, all of which are preceded by a blank space, four of which are also followed by a blank space, one of which is followed by a period. This count is also in accordance with our intuitive feeling of what a word is. Even without this somewhat formal and technical definition, you might want to argue, you could have told that the sentence in (1) contains five words. However, things are not always as straightforward. Consider the following example, and try to determine how many words there are:

(2) Benjamin's girlfriend lives in a high-rise apartment building 
Your result depends on a number of assumptions. If you consider apostrophes to be punctuation marks, Benjamin's constitutes two (orthographic) words. If not, Benjamin's is one word. If you consider a hyphen a punctuation mark, high-rise is two (orthographic) words, otherwise it's one (orthographic) word. The last two strings, apartment building, are easy to classify, they are two (orthographic) words, whereas girlfriend must be considered one (orthographic) word. However, there are two basic problems with our orthographic analysis. The first one is that orthography is often variable. Thus, girlfriend is also attested with the spellings < girl-friend>, and even < girl friend> (fish brackets are used to indicate spellings, i.e. letters). Such variable spellings are rather common (cf. word-formation, word formation, and word formation, all of them attested), and even where the spelling is conventionalized, similar words are often spelled differently, as evidenced with grapefruit vs. passion fruit. For our problem of defining what a word is, such cases are rather annoying. The notion of what a word is, should, after all, not depend on the fancies of individual writers or the arbitrariness of the English spelling system. The second problem with the orthographically defined word is that it may not always coincide with our intuitions. Thus, most of us would probably agree that girlfriend is a word (i.e. one word) which consists of two words (girl and friend), a so-called compound. If compounds are one word, they should be spelled without a blank space separating the elements that together make up the compound. Unfortunately, this is not the case. The compound apartment building, for example, has a blank space between apartment and building.

But there is another way of how the sound structure can tell us something about the nature of the word as a linguistic unit. Think of stress. In many languages (including English) the word is the unit that is crucial for the occurrence and distribution of stress. Spoken in isolation, every word can have only one main stress, as indicated by the acute accents ( ${ }^{\prime}$ ) in the data presented in (3) below (note that we speak of linguistic 'data' when we refer to language examples to be analyzed).

$\begin{array}{ll}\text { (3) } \text { Carpenter } & \text { Textbook } \\ \text { Water } & \text { Analysis } \\ \text { Federal } & \text { Syllable } \\ \text { Mother } & \text { Understand }\end{array}$

The main stressed syllable is the syllable which is the most prominent one in a word. Prominence of a syllable is a function of loudness, pitch and duration, with stressed syllables being pronounced louder, with higher pitch, or with longer duration than the neighboring syllable(s). Longer words often have additional, weaker stresses, so called secondary stresses, which we ignore here for simplicity's sake. The words in (4) now show that the phonologically defined word is not always identical with the orthographically defined word.

\section{MORPHEMES}

The morpheme is defined as the (Matthews, P. H.1991), states is the smallest meaning-bearing unit. It is a minimal unit of meaning because it cannot be further broken down into smaller meaningful units. For example, $\{$ freeze $\}$ can be divided in a number of ways, e.g., fr-eeze, free-ze, fre-eze, but none of these divisions produces two meaningful units. Further division only results in phonological units, devoid of predictable or consistent meaning.

The two characteristics that most typically indicate the presence of a common morpheme across words are similar meanings and a common phonological string. Words that only share a phonological form, such as those in (4), or only share meaning components, such as those in (5), do not necessarily contain a common morpheme.

$$
\begin{aligned}
& \text { (4) a. under, uncle } \\
& \text { b. table, cable, stable } \\
& \text { (5) a. run, jog } \\
& \text { b. speak, say, talk, tell } \\
& \text { c. couch, sofa }
\end{aligned}
$$

In addition to capturing a relationship between words like happy and unhappy, morphemes have been argued to allow for a more economical storage system. The repository for words and/or morphemes in 
memory is called the lexicon. For many years it was thought that there was a premium on storage space in the lexicon. Economy of storage was highly valued and thus, predictable information, such as the consistent form and meaning between two related words, was absent from the lexicon. Redundant full word representations such as happy, unhappy, happiness, happily, unhappiness, unhappily, etc, were replaced with economical morpheme representations, namely $\{$ happy $\},\{$ un- $\},\{$-ness $\}$, and $\{-$ ly\}, which can be combined to create predictable complex words.

\section{ALLOMORPH}

Morphemes have invariable realizations. That is, we have assumed that one meaning is expressed by a certain morph or a certain string of morphs and not by variable morphs whose exact shape differs according to the context in which they occur. However, this is exactly the kind of situation we find with many morphemes, be they bound or free. For instance, the definite and indefinite articles in English take on different shapes, depending on the kind of word which they precede:

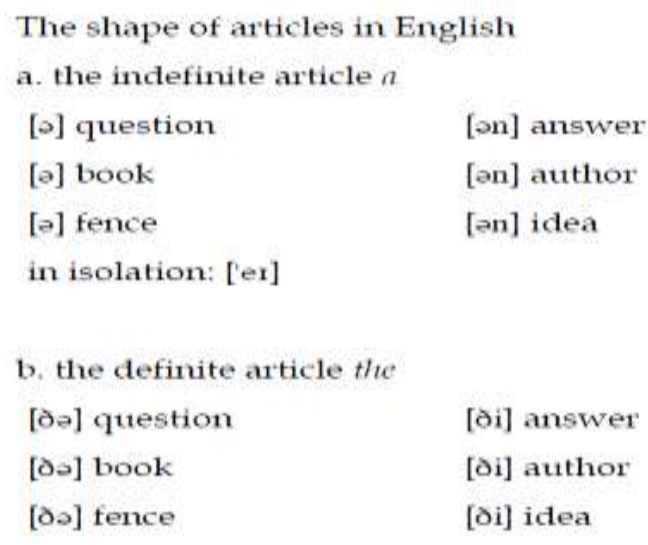

in isolation: ['oi]

\section{DERIVATIONAL AND INFLECTIONAL AFFIXES}

Derivation and inflection are two functional categories of change in morphology (suffix, prefix, etc. are formal categories, since they refer to the form of the change). An affix or other chunk of morphology is usually either derivational or inflectional, though there is certain grey area between them.

Most of the affixes we are familiar with in English are derivational, English has eight inflectional affixes. Bellow are 5 characteristic that distinguish inflections from derivation.

\begin{tabular}{|c|c|c|}
\hline No. & Derivational Morphemes & Inflectional Morphemes \\
\hline 1. & $\begin{array}{l}\text { Can change part of speech or meaning, e,g - ment } \\
\text { forms nouns such as judgement from verbs such } \\
\text { as judgement. }\end{array}$ & $\begin{array}{l}\text { Do not change part of speech or meaning, eg, big and } \\
\text { bigger are both adjectives. }\end{array}$ \\
\hline 2. & $\begin{array}{l}\text { Typically indicate semantic relations within the } \\
\text { word,e,g,the morpheme-ful as in painful has no } \\
\text { particular connection with any morpheme in a } \\
\text { sentence, beyond, the word painful. Itself. }\end{array}$ & $\begin{array}{l}\text { Typically indicate semantic or syntactic relation } \\
\text { between different words in a sentence,e.g the present } \\
\text { tense morpheme } s \text { in waits shows agreement with the } \\
\text { subjet of the verb (both the third person singular) }\end{array}$ \\
\hline 3. & $\begin{array}{l}\text { Typically occur with only some members of a } \\
\text { class of morphemes,e,g the suffix hood Occurs } \\
\text { with just a few nouns such as brother, } \\
\text { neighborand night but not with most others, e.g } \\
\text { friend, daughter, candle. }\end{array}$ & $\begin{array}{l}\text { Typically occur with all members of some large class } \\
\text { of morphemes, e.g the plural morpheme } s \text { occurs with } \\
\text { almost all count nouns in English }\end{array}$ \\
\hline 4. & $\begin{array}{l}\text { Typically occur before inflectional suffixes and } \\
\text { after inflectional prefixes, tough not in English. }\end{array}$ & $\begin{array}{l}\text { Typically occur at the margins of words, e.g the plural } \\
\text { morphemes } s \text { comes last in an English word such as } \\
\text { babysitters }\end{array}$ \\
\hline 5. & $\begin{array}{l}\text { Instantiate a single category, which may be } \\
\text { complex, but never occurs in a paradigm, e.g } \\
\text { there is no paradigm of all the ways there are of } \\
\text { forming verbs from nouns, just scattered } \\
\text { processes on different words. }\end{array}$ & $\begin{array}{l}\text { Can instantiate categories that occur in paradigmatic } \\
\text { sets,e.g the categories of number and person produce } \\
\text { the various forms of the verb e.g I am, You are, He is }\end{array}$ \\
\hline
\end{tabular}




\section{SUMMARY}

The researcher has touched lightly on the issue of acronyms as part of word processes, while dealt in an in depth handling with certain parts of morphology.

\section{REFERENCES}

[1] Hurrford, James Semantics: a Course book (2007:60) ( $2^{\text {nd }}$ Edition) Cambridge University Press

[2] Jindal D.V. An Introduction to Linguistics (2007:3), ( $2^{\text {nd }}$ Edition): Prentice Hall of India, New Delhi

[3] Akmajian A., Demers R., Farmer A., Harnish R. An Introduction to Language and Communication (1997:12), (4 ${ }^{\text {th }}$ Edition): The MIT Press, Cambridge, Massachusetts, London, England

[4] Fromkin V., Rodman R., Hyams N. An Introduction to Language(2003:107), (7 $7^{\text {th }}$ Edition): Thomson Heinle

[5] Fromkin V., Rodman R., Hyams N. An Introduction to Language(2003:77), ( $7^{\text {th }}$ Edition): Thomson Heinle

[6] Crystal D. A Dictionary of Linguistics and Phonetics (2003:300), (5 ${ }^{\text {th }}$ Edition): Blackwell Publishing

[7] Jindal D.V. An Introduction to Linguistics (2007:77), ( $2^{\text {nd }}$ Edition): Prentice Hall of India, New Delhi

[8] W. Fasold R. An Introduction to Language and Linguistics (2006:61), ( $1^{\text {st }}$ Edition): Cambridge University Press

[9] H.G. Widdowson Linguistics (1996:46), ( $\left({ }^{\text {st }}\right.$ Edition): Oxford University Press

[10] H.G. Widdowson Linguistics (1996:47), ( $1^{\text {st }}$ Edition): Oxford University Press

[11] S. Falik J. Linguistics and Language (1978:30), ( $2^{\text {nd }}$ Edition): john Wiley and Sons / New York/ Santa Barbara

[12] W. Alison, B. Aileen Projects In Linguistics (2006:69), (2 ${ }^{\text {nd }}$ Edition): Oxford University Press Inc.

Citation: Mohamed Said Ahmed Alawad "Exploring the Concept of Acronyms form a Morphological Viewpoint" International Journal of Humanities Social Sciences and Education (IJHSSE), vol 5, no. 1, 2018, pp. 1-5. doi: http://dx.doi.org/10.20431/2349-0381.0501001.

Copyright: () 2018 Authors. This is an open-access article distributed under the terms of the Creative Commons Attribution License, which permits unrestricted use, distribution, and reproduction in any medium, provided the original author and source are credited 